\title{
The $80-k b$ DNA duplication on BTA1 is the only remaining candidate mutation for the polled phenotype of Friesian origin
}

\author{
Sophie Rothammer ${ }^{1}$, Aurélien Capitan ${ }^{2,3,4}$, Erik Mullaart ${ }^{5}$, Doris Seichter ${ }^{6}$, Ingolf Russ ${ }^{6}$ and Ivica Medugorac ${ }^{1 *}$
}

\begin{abstract}
Background: The absence of horns, called polled phenotype, is the favored trait in modern cattle husbandry. To date, polled cattle are obtained primarily by dehorning calves. Dehorning is a practice that raises animal welfare issues, which can be addressed by selecting for genetically hornless cattle. In the past 20 years, there have been many studies worldwide to identify unique genetic markers in complete association with the polled trait in cattle and recently, two different alleles at the POLLED locus, both resulting in the absence of horns, were reported: (1) the Celtic allele, which is responsible for the polled phenotype in most breeds and for which a single candidate mutation was detected and (2) the Friesian allele, which is responsible for the polled phenotype predominantly in the Holstein-Friesian breed and in a few other breeds, but for which five candidate mutations were identified in a 260-kb haplotype. Further studies based on genome-wide sequencing and high-density SNP (single nucleotide polymorphism) genotyping confirmed the existence of the Celtic and Friesian variants and narrowed down the causal Friesian haplotype to an interval of $145 \mathrm{~kb}$.
\end{abstract}

Results: Almost 6000 animals were genetically tested for the polled trait and we detected a recombinant animal which enabled us to reduce the Friesian POLLED haplotype to a single causal mutation, namely a 80-kb duplication. Moreover, our results clearly disagree with the recently reported perfect co-segregation of the POLLED mutation and a SNP at position 1390292 bp on bovine chromosome 1 in the Holstein-Friesian population.

Conclusion: We conclude that the 80-kb duplication, as the only remaining variant within the shortened Friesian haplotype, represents the most likely causal mutation for the polled phenotype of Friesian origin.

\section{Background}

The bovine polled phenotype, i.e. the absence of horns, has huge practical importance for breeders and is of special biological interest to geneticists. Currently, the world cattle population is estimated to be about 1.3 billion heads [1] of which a large proportion is horned. Although historical records indicate the presence of naturally polled cattle as far back as ancient Egypt [2,3], until recently, horned cattle remained the desired phenotype because it simplified tethering and attachment to harnesses. However, in modern husbandry systems, such practices are no longer used and the presence of horns increases the risk of injuries to handlers and animals, especially as the housing densities have

\footnotetext{
* Correspondence: ivica.medjugorac@gen.vetmed.uni-muenchen.de 'Animal Genetics and Husbandry, Ludwig-Maximilians-University Munich, Veterinärstraße 13, 80539 Munich, Germany

Full list of author information is available at the end of the article
}

increased. Thus, the presence of horns induces considerable economic losses in the cattle industry due to dehorning practices and the treatment of subsequent secondary infections, but also due to carcass and leather deterioration [2,4-7]. Today, dehorning of cattle at an early age is common and although records are not exhaustive, there are probably more than 100 million calves that are dehorned each year. Since all dehorning methods are invasive and thus raise animal welfare issues, the possibility of breeding genetically polled cattle is a promising alternative $[4,8]$. In addition, understanding the molecular mechanisms that are involved in the inhibition of the bovine horn bud differentiation will contribute knowledge on the mechanisms that underlie ectopic expression in mammals [2].

Since 1906, the polled phenotype is known to be inherited as an autosomal dominant trait [9] and the POLLED locus was mapped to bovine chromosome 1 (BTA1 for Bos 
taurus) in 1993 [10]. In the past years, the position of the POLLED locus on BTA1 was refined $[11,12]$ and candidate causal mutations were identified $[2,4,5]$. Recently, Medugorac et al. [4] demonstrated the existence of at least two different alleles at the POLLED locus in cattle. While a complex 202-bp insertion-deletion (InDel), referred to as $\mathrm{P}_{202 \mathrm{ID}}$, was identified in various cattle breeds from Scandinavia, Scotland, England, the Channel Islands and France down to the Alpine region (thus also referred to as the Celtic allele $\mathrm{P}_{\mathrm{C}}$ ), a 260-kb haplotype including five candidate mutations (three SNP: $\mathrm{P}_{\mathrm{G} 1654405 \mathrm{~A}}, \mathrm{P}_{\mathrm{C1655463T}}$, $\mathrm{P}_{\mathrm{C} 1768587 \mathrm{~A}}$; two InDel: $\left.\mathrm{P}_{5 \mathrm{ID}}, \mathrm{P}_{80 \mathrm{kbID}}\right)$ was reported to be perfectly associated with the polled phenotype in the HolsteinFriesian breed (thus also referred to as the Friesian allele $\mathrm{P}_{\mathrm{F}}$ ) [4]. Further studies based on genome-wide sequencing and high-density SNP genotyping confirmed the existence of these Celtic and Friesian variants and narrowed the causal Friesian haplotype down to an interval of $145 \mathrm{~kb}$ [2] that included only two of the five initial candidate mutations i.e. SNP $\mathrm{P}_{\mathrm{C} 1768587 \mathrm{~A}}$ and InDel $\mathrm{P}_{80 \mathrm{kbID}}$. However, highthroughput sequencing of this $145-\mathrm{kb}$ interval identified two new candidate variants i.e. SNPs $\mathrm{P}_{\mathrm{T} 1764239 \mathrm{C}}$ and $\mathrm{P}_{\mathrm{G} 1855898 \mathrm{~A}}$, and genotyping of an enlarged cattle breed panel revealed the presence of the Celtic allele in new breeds from Iceland, Scandinavia, UK, Ireland and France [2]. In 2013, Allais-Bonnet et al. [2] provided evidence that introgression of the Friesian allele was ongoing in some French and German cattle breeds for which the Celtic allele was predominant and Glatzer et al. [5] reported that SNP AC000158:g.1390292G > A, hereinafter referred to as rs134968598, co-segregated perfectly with the POLLED locus in a set of 443 Holstein-Friesian animals. This SNP is located within intron 3 of the interferon gamma receptor 2 (IFNGR2) gene and is close (1113 bp) to a SNP for which the most significant selection signature was observed in a group of polled cattle [13]. However, these two SNPs are located $378 \mathrm{~kb}$ from the above mentioned Friesian haplotype.

This study aimed at (1) refining the 260-kb haplotype which, based on previous results, is associated with the polled phenotype of Friesian origin [4] and (2) examining the co-segregation of SNP rs134968598 and the POLLED locus in Holstein-Friesian cattle. These aims are highly interesting from a practical and economic point of view for the most important global cattle breed Holstein-Friesian. Identification of the causal candidate mutation in the Friesian haplotype will also contribute to decipher the molecular mechanisms that underlie this complex developmental phenotype with allelic heterogeneity.

\section{Methods}

\section{Ethical statement}

No formal ethical approval was required, since no new tissue samples were collected for this study. Indeed, for most animals, the DNA samples from previous studies $[4,12]$ were in stock in our laboratory and the remaining DNA samples were obtained from routine testing (paternity and polled phenotype test) by appropriate cattle breeding organizations.

\section{Animal samples}

A total of 5993 bovine individuals were genotyped for the Celtic allele $\mathrm{P}_{\text {202ID }}$ and for the two InDel mutations that flank the Friesian haplotype i.e. $\mathrm{P}_{5 \mathrm{ID}}$ and $\mathrm{P}_{80 \mathrm{kbID}}$ (Figure 1A) using previously described methods [4]. A small proportion of these animals was also genotyped for the three other mutations in the Friesian haplotype i.e. (i) animals that were shown to carry both the Celtic and the Friesian alleles on two different chromosomes $(\sim 1.2 \%)$, (ii) animals that were recombinant within the Friesian haplotype $(\sim 0.02 \%)$ and (iii) a few animals that displayed an initial ambiguous genotyping result $(\sim 1.5 \%)$. To refine the Friesian haplotype, we included the two recombinant animals and all their available ancestors and relatives, which constituted a pedigree of 13 genotyped Holstein-Friesian animals (Figure 1B).

To test the previously reported [5] co-segregation of the POLLED locus with SNP rs134968598, which is located outside of the 260-kb haplotype, we used 130 animals that were representative of the global polled and horned Holstein-Friesian cattle population. These 130 animals included animals that we also used to refine the Friesian haplotype and bulls that had already been analyzed in our previous study [4]. Of the 130 animals, 69 were horned (pp), 54 were heterozygous polled (Pp) and seven were homozygous polled (PP). The POLLED genotype of each polled bull based on progeny testing was available from the respective breeding organizations. The progeny test considered phenotypes of at least nine progeny per bull mated to horned dams.

\section{Sequencing of the $\mathrm{P}_{\mathrm{T} 1764239 \mathrm{C}}$ candidate mutation}

In our previous study, the region captured around the SNP $\mathrm{P}_{\mathrm{T} 1764239 \mathrm{C}}$, one of the two new candidate SNPs reported by [2], was sequenced by high-throughput sequencing, but the sequence coverage was low [4]. Therefore, this region was re-sequenced by conventional Sanger sequencing [14] using DNA samples from four horned animals for which, in the previous study, the sequence capture data suggested a discrepancy between the known phenotype and the expected genotype, although the coverage was too low to infer reliable genotypes.

\section{Refining the Friesian haplotype}

In order to refine the 260-kb haplotype that perfectly associates with the POLLED locus of Friesian origin, we genotyped 13 Holstein-Friesian individuals (that formed a small pedigree with two recombinant bulls and 11 relatives) for 


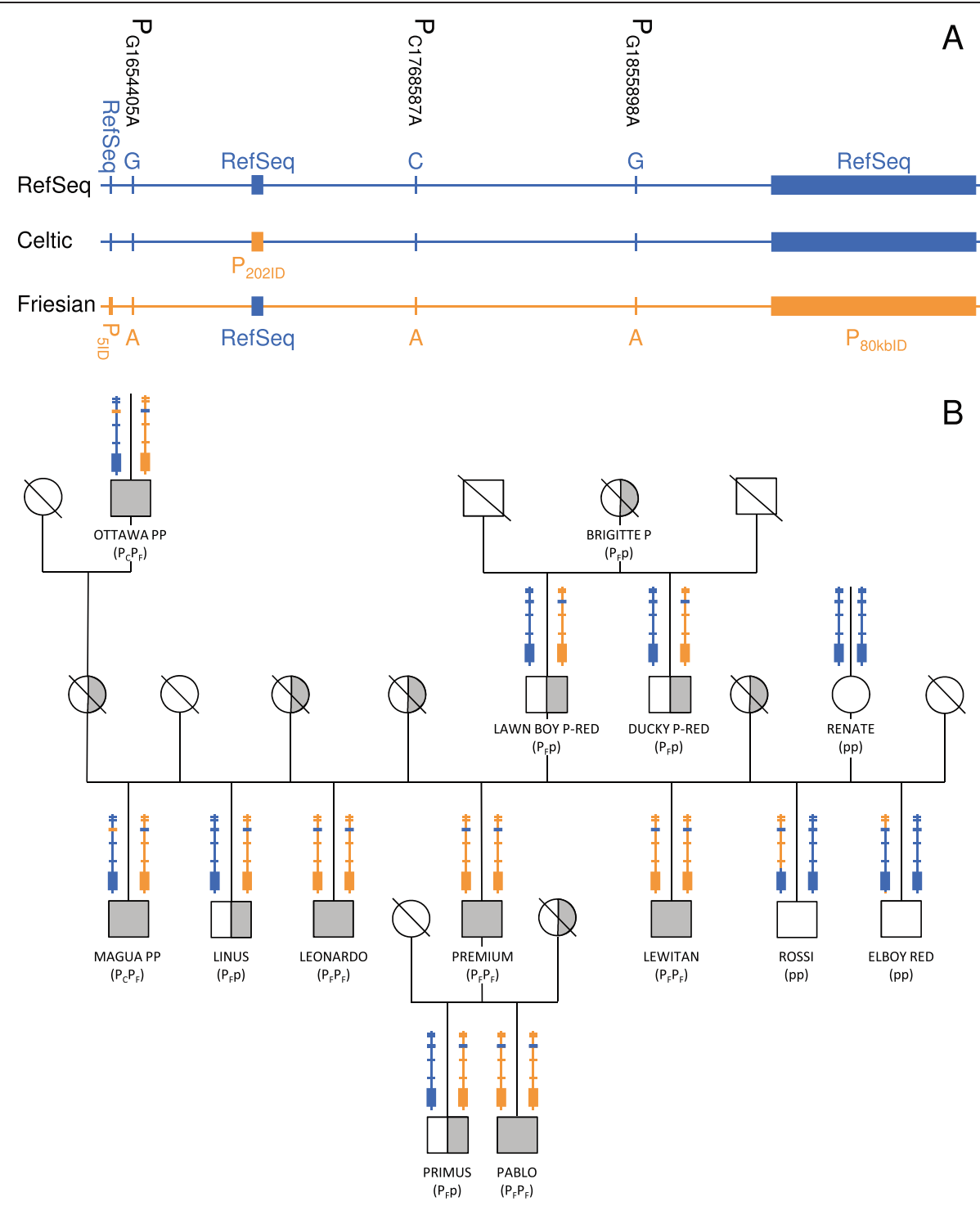

Figure 1 Polled phenotype of Friesian origin. A) Relative position of the candidate mutations for the polled phenotype of Celtic $\left(P_{C}\right)$ and Friesian $\left(P_{F}\right)$ origin. All reference sequence (RefSeq) alleles are shown in blue and POLLED candidate mutations in orange. The insertion-deletion events $\left(P_{5 \mid D}, P_{2021 D}\right.$ and $\left.P_{80 k b l D}\right)$ are presented as bars and SNPs as lines. Note that this figure does not include the fairly distant SNP rs 134968598 at position 1390292 bp. B) Pedigree of 13 Holstein-Friesian animals used to narrow down the interval containing the POLLED mutation of Friesian origin. Color code is as above. The recombinant haplotypes of the ROSSI and ELBOY RED bulls are shown with the corresponding colors. Polled homozygous (PP) individuals are represented by solid circles (females) and squares (males); declared polled heterozygous animals (Pp) by half-filled symbols; horned animals (pp) by empty symbols; missing and ungenotyped individuals are marked with a diagonal line.

the Celtic allele $\mathrm{P}_{202 \mathrm{ID}}$ and the four Friesian variants $\mathrm{P}_{5 \mathrm{ID}}$, $\mathrm{P}_{\mathrm{G} 1654405 \mathrm{~A}}, \mathrm{P}_{\mathrm{C} 1768587 \mathrm{~A}}$ and $\mathrm{P}_{80 \mathrm{kbID}}$ as described in Medugorac et al. [4]. Furthermore, of the two additional Friesian SNPs $\mathrm{P}_{\mathrm{G} 1855898 \mathrm{~A}}$ and $\mathrm{P}_{\mathrm{T} 1764239 \mathrm{C}}$ reported in Allais-Bonnet et al. [2], we included only the candidate causal mutation $\mathrm{P}_{\mathrm{G} 1855898 \mathrm{~A}}$ because preliminary Sanger sequencing results indicated that $\mathrm{P}_{\mathrm{T} 1764239 \mathrm{C}}$ segregated in horned animals. Thus, the 13 Holstein-Friesian individuals were also genotyped for $\mathrm{P}_{\mathrm{G} 1855898 \mathrm{~A}}$ using PCR-RFLP. Therefore, PCR products of the region around $\mathrm{P}_{\mathrm{G} 1855898 \mathrm{~A}}$ were amplified using the primers reported in [2], digested with the restriction enzyme PstI and the digestion products were size-separated by electrophoresis on a $2 \%$ ethidium-bromide stained agarose gel.

\section{Genotyping of SNP rs134968598 to test co-segregation with the POLLED locus}

The 130 animals, including those used to refine the haplotype, were genotyped for the recently published mutation within the gene IFNGR2 (rs134968598) as described in Glatzer et al. [5]. 


\section{Results and discussion}

\section{Genotyping of SNP rs134968598 to test co-segregation} with the POLLED locus

Recently, Glatzer et al. [5] reported that SNP rs134968598 co-segregated with the POLLED locus in a set of 443 (15 PP, 71 Pp, 357 pp) Holstein-Friesian animals [5]. In our study, genotyping of 130 animals representative of the global polled and horned Holstein-Friesian cattle population (7 PP, 54 Pp, 69 pp) for SNP rs134968598 revealed discrepancies between the progeny-based genotypes and the SNP-based genotypes at the POLLED locus in seven cases (see Table 1). Of the 69 genotyped horned individuals (POLLED genotype pp), 67 were homozygous G/G for rs134968598 as expected according to [5] but two bulls were heterozygous $\mathrm{A} / \mathrm{G}$. Of the 54 proven heterozygous polled ( $\mathrm{Pp}$ ) bulls, 51 were heterozygous $\mathrm{A} / \mathrm{G}$ and three were homozygous G/G. Finally, five of the seven proven homozygous polled bulls (PP) were homozygous $\mathrm{A} / \mathrm{A}$, but two were heterozygous $\mathrm{A} / \mathrm{G}$. In conclusion, $\sim 5 \%$ of the genotypes at SNP rs134968598 are inconsistent with the previously reported perfect co-segregation between this SNP and the POLLED locus in Holstein-Friesian cattle. Similar to Glatzer et al. [5], our sample of 130 animals was representative of the global Holstein-Friesian population (i.e. from Canada, the Czech Republic, Denmark, France, Germany, Italy, the Netherlands and the United States of America) and among the polled individuals that exclude SNP rs134968598, some are major breeding bulls like the homozygous polled PREMIUM PP bull which has been extensively used in recent years.

\section{Refining the Friesian haplotype}

After our genotyping data excluded the rs134968598 SNP on BTA1 at position 1390292 bp as a candidate mutation, we re-analysed our sequence capture data and partly re-sequenced a region around the $\mathrm{P}_{\mathrm{T} 1764239 \mathrm{C}}$ candidate mutation of the 145 -kb haplotype of Friesian origin reported in Allais-Bonnet et al. [2]. Several horned animals were found heterozygous $\mathrm{C} / \mathrm{T}$ at $\mathrm{SNP} \mathrm{P}_{\mathrm{T} 1764239 \mathrm{C}}$ and thus this SNP was also excluded as a candidate mutation. In order to refine the Friesian haplotype, which

Table 1 Seven bulls for which the progeny-based POLLED genotype and the genotype at SNP rs134968598 did not match

\begin{tabular}{llll}
\hline Breeding bull & International ID & Polled & rs134968598 \\
\hline ELBOY RED & FRAM000109031700 & $\mathrm{pp}$ & $\mathrm{A} / \mathrm{G}$ \\
ROSSI & NLDM000538994750 & $\mathrm{pp}$ & $\mathrm{A} / \mathrm{G}$ \\
JOSEF PS & DEUM000768421954 & $\mathrm{Pp}$ & $\mathrm{G} / \mathrm{G}$ \\
LEGOLAS P & DEUM000352976294 & $\mathrm{Pp}$ & $\mathrm{G} / \mathrm{G}$ \\
PRIMUS P & DEUM000536884209 & $\mathrm{Pp}$ & $\mathrm{G} / \mathrm{G}$ \\
PABLO PP & DEUM000769554302 & $\mathrm{PP}$ & $\mathrm{A} / \mathrm{G}$ \\
PREMIUM PP & USAM000139419625 & $\mathrm{PP}$ & $\mathrm{A} / \mathrm{G}$ \\
\hline
\end{tabular}

contains the causal mutation for the polled trait in most Holstein-Friesian breeding lines, a small pedigree including two recombinant bulls and relatives (Figure 1B) was genotyped for the six known polymorphisms in this region $\mathrm{P}_{\text {202ID, }} \mathrm{P}_{5 \text { ID }}, \mathrm{P}_{\mathrm{G} 1654405 \mathrm{~A}}, \mathrm{P}_{\mathrm{C} 1768587 \mathrm{~A}}, \mathrm{P}_{\mathrm{A} 1855898 \mathrm{G}}$ and $\mathrm{P}_{\text {80kbID }}$ (for physical positions (according to UMD3.1) see Figure 1A).

ELBOY RED, a horned male offspring of LAWN BOY PRED, is a recombinant between $\mathrm{P}_{\mathrm{G1654405A}}$ and $\mathrm{P}_{\mathrm{C} 1768587 \mathrm{~A}}$, which excludes $\mathrm{P}_{5 I D}$ and $\mathrm{P}_{\mathrm{G} 1654405 \mathrm{~A}}$ as well as the fairly distant rs134968598 SNP as candidate mutations for the polled phenotype. Previously, we reported and confirmed this recombination in 20 horned offspring of ELBOY RED [2]. A second horned offspring of LAWN BOY P-RED, the recombinant bull ROSSI, carries a large region of the Friesian haplotype that is associated with the polled trait and that comprises $\mathrm{P}_{5 I D}, \mathrm{P}_{\mathrm{G} 1654405 \mathrm{~A}}, \mathrm{P}_{\mathrm{C} 1768587 \mathrm{~A}}$ and $\mathrm{P}_{\mathrm{G} 1855898 \mathrm{~A}}$ (Figure $1 \mathrm{~A}$ and $\mathrm{B}$ ). The genotyping data of ROSSI located the recombination event in an interval of $53 \mathrm{~kb}$ between $\mathrm{P}_{\mathrm{G} 1855898 \mathrm{~A}}$ and $\mathrm{P}_{80 \mathrm{kbID}}$ (beginning at g.1909352) and clearly excluded $\mathrm{P}_{5 \mathrm{ID}}, \mathrm{P}_{\mathrm{G} 1654405 \mathrm{~A}}, \mathrm{P}_{\mathrm{C} 1768587 \mathrm{~A}}$ and $\mathrm{P}_{\mathrm{G} 1855898 \mathrm{~A}}$ as candidates for the polled phenotype of Friesian origin.

Finally, based on the combined sequencing and genotyping data from our previous studies $[2,4]$ and this study, the only remaining causal candidate within the Friesian POLLED haplotype is the $80-\mathrm{kb}$ duplication $\mathrm{P}_{80 \mathrm{kbID}}$. This conclusion is inconsistent with that of Glatzer et al. [5] who reported the existence of a progeny-proven heterozygous polled Holstein-Friesian sire that carried neither the $\mathrm{P}_{80 \mathrm{kbID}}$ mutation nor a Celtic mutation. Unfortunately, since the identity of this bull was not provided, we could not verify these results. However, our personal experience from different previous analyses that we carried out is, that reliable genotyping of $\mathrm{P}_{202 \mathrm{ID}}$ and $\mathrm{P}_{80 \mathrm{kbID}}$ is not trivial and that the genotyping-procedure should be validated using anonymous samples. Thus, there is a possibility that the bull reported in [5] does carry either $\mathrm{P}_{202 \mathrm{ID}}$ or $\mathrm{P}_{80 \mathrm{kbID}}$. In addition, even if we had demonstrated the absence of both $\mathrm{P}_{202 \mathrm{ID}}$ and $\mathrm{P}_{80 \mathrm{kbID}}$ in the genome of this bull, further analyses would still have been necessary to show that it does not carry another spontaneous mutation, which could be responsible for a dominant horn defect syndrome. Such mutations have been reported to occur and can be confused with the regular POLLED locus $[2,15,16]$. Therefore, the existence of a new candidate mutation at the POLLED locus of this animal should first be investigated and supported by linkage analyses on its relatives before refuting the highly probable causality of $\mathrm{P}_{80 \mathrm{kbID}}$ for the polled phenotype in Holstein-Friesian cattle.

\section{Conclusions}

Based on the genotypes of almost 6000 animals, we identified two bulls with a recombination within the 260-kb Friesian haplotype and narrowed this haplotype down to 
an interval of $53 \mathrm{~kb}$ on BTA1. Moreover, the results from these two recombinant bulls and related individuals disagree with the perfect association between the POLLED locus and a SNP within intron 3 of the IFNGR2 gene previously reported by Glatzer et al. [5]. Combining the exhaustive sequencing data and high-density SNP genotyping results from previous studies $[2,4]$ and those reported here, we provide evidence that supports the $\mathrm{P}_{80 \mathrm{kbID}}$ mutation as the only remaining and most likely causal mutation for the polled phenotype of Friesian origin. In addition to $\mathrm{P}_{80 \mathrm{kbID}}$, $\mathrm{P}_{\text {202ID }}$ (the POLLED mutation of Celtic origin) segregates in some Holstein-Friesian families and sporadically combines in some homozygous polled but heterogeneous $\left(\mathrm{P}_{\mathrm{C}} /\right.$ $\mathrm{P}_{\mathrm{F}}$ ) animals (Figure 1B). Neither $\mathrm{P}_{80 \mathrm{kbID}}$ nor $\mathrm{P}_{\text {202ID }}$ are located in any known coding regions $[2,4]$ but these mutations, even as single copy, result in the inhibition of horn development at a very early stage in cattle $[2,4]$. Therefore, future investigations of the molecular mechanisms that underlie the inhibition of horn development in cattle will enrich our knowledge not only on the mechanisms that are involved in bovine horn bud differentiation but, also, more generally, on ectopic expression in mammals.

\section{Competing interests}

The authors declare that they have no competing interests.

\section{Authors' contributions}

SR contributed to molecular genetics and statistical analyses, drafted and revised the manuscript. AC provided samples, phenotyped animals, analysed the data and critically revised the manuscript. EM provided samples, phenotyped animals and contributed to the interpretation of data. DS and IR contributed to molecular genetics analyses and provided samples and phenotypes. IM designed the study and performed statistical analyses, drafted and critically reviewed the manuscript. All authors read and approved the final manuscript.

\section{Acknowledgments}

We thank breeders, breeding organizations and insemination stations, which provided samples for this study. In particular, we thank KH Göpel (Göpel Genetik GmbH, Germany), Dr J Potthast (RUW, Germany), Dr B Weber (Masterrind GmbH, Germany), B Brentrup (WWS Germany GmbH, Germany), C Grohs (INRA, France) and J Thomin (Evolution, France) for sharing samples and phenotypes. We thank the reviewers and editor for their helpful comments, which have greatly improved language, content and clarity of the paper.

\section{Author details \\ 'Animal Genetics and Husbandry, Ludwig-Maximilians-University Munich, Veterinärstraße 13, 80539 Munich, Germany. ${ }^{2}$ INRA, UMR1313 Génétique Animale et Biologie Intégrative, F-78352 Jouy-en-Josas, France. \\ ${ }^{3}$ AgroParisTech, UMR1313 Génétique Animale et Biologie Intégrative, F-75231 Paris 05, France. ${ }^{4}$ UNCEIA, Service Génétique, Paris, France. ${ }^{5}$ CRV BV, P.O. Box 454, Arnhem, The Netherlands. ${ }^{6}$ Tierzuchtforschung e.V. München, \\ Senator-Gerauer-Straße 23, 85586 Grub, Germany.}

Received: 30 December 2013 Accepted: 17 May 2014

Published: 3 July 2014

\section{References}

1. Brown LR: Plan B 4.0: Mobilizing to Save Civilization. New York: WW Norton \& Company; 2009

2. Allais-Bonnet A, Grohs C, Medugorac I, Krebs S, Djari A, Graf A, Fritz S, Seichter D, Baur A, Russ I, Bouet S, Rothammer S, Wahlberg P, Esquerre D, Hoze C, Boussaha M, Weiss B, Thepot D, Fouilloux MN, Rossignol MN, van Marle-Koster E, Hreietharsdottir GE, Barbey S, Dozias D, Cobo E, Reverse P, Catros $\mathrm{O}$, Marchand $J \mathrm{~L}$, Soulas P, Roy P, et al: Novel insights into the bovine polled phenotype and horn ontogenesis in Bovidae. PLOS ONE 2013, 8:e63512.

3. Roman A: L'élevage bovine en Egypte antique. Bull Soc Fr Hist Méd Sci Vét 2004, 3:35-45.

4. Medugorac I, Seichter D, Graf A, Russ I, Blum H, Gopel KH, Rothammer S, Förster $\mathrm{M}$, Krebs S: Bovine polledness-an autosomal dominant trait with allelic heterogeneity. PLOS ONE 2012, 7:e39477.

5. Glatzer S, Merten NJ, Dierks C, Wöhlke A, Philipp U, Distl O: A Single nucleotide polymorphism within the Interferon Gamma Receptor 2 gene perfectly coincides with polledness in Holstein cattle. PLOS ONE 2013, 8:e67992.

6. Misch LJ, Duffield TF, Millman ST, Lissemore KD: An investigation into the practices of dairy producers and veterinarians in dehorning dairy calves in Ontario. Can Vet J 2007, 48:1249-1254.

7. Prayaga KC: Genetic options to replace dehorning in beef cattle - a review. Aust J Agr Res 2007, 58:1-8.

8. Graf B, Senn M: Behavioural and physiological responses of calves to dehorning by heat cauterization with or without local anaesthesia. Appl Anim Behav Sci 1999, 62:153-171.

9. Spillman WJ: Mendel's law in relation to animal breeding. J Hered 1906, 1:171-177.

10. Georges M, Drinkwater R, King T, Mishra A, Moore SS, Nielsen D, Sargeant LS, Sorensen A, Steele MR, Zhao X, Womack JE, Hetzel J: Microsatellite mapping of a gene affecting horn development in Bos taurus. Nat Genet 1993, 4:206-210.

11. Drögemuller $\mathrm{C}$, Wöhlke $\mathrm{A}$, Mömke $\mathrm{S}$, Distl O: Fine mapping of the polled locus to a 1-Mb region on bovine chromosome 1q12. Mamm Genome 2005, 16:613-620.

12. Seichter D, Russ I, Rothammer S, Eder J, Förster M, Medugorac I: SNP-based association mapping of the polled gene in divergent cattle breeds. Anim Genet 2012, 43:595-598

13. Stella A, Ajmone-Marsan P, Lazzari B, Boettcher P: Identification of selection signatures in cattle breeds selected for dairy production. Genetics 2010, 185:1451-1461.

14. Sanger F, Nicklen S, Coulson AR: DNA sequencing with chain-terminating inhibitors. Proc Natl Acad Sci USA 1977, 74:5463-5467.

15. Capitan A, Allais-Bonnet A, Pinton A, Marquant-Le Guienne B, Le Bourhis D, Grohs C, Bouet S, Clement L, Salas-Cortes L, Venot E, Chaffaux S, Weiss B, Delpeuch A, Noe G, Rossignol MN, Barbey S, Dozias D, Cobo E, Barasc H, Auguste A, Pannetier M, Deloche MC, Lhuilier E, Bouchez O, Esquerre D, Salin G, Klopp C, Donnadieu C, Chantry-Darmon C, Hayes H, et al: A 3.7 Mb deletion encompassing ZEB2 causes a novel polled and multisystemic syndrome in the progeny of a somatic mosaic bull. PLOS ONE 2012, 7:e49084.

16. Capitan A, Grohs C, Weiss B, Rossignol MN, Reversé P, Eggen A: A newly described bovine type 2 scurs syndrome segregates with a frame-shift mutation in TWIST1. PLOS ONE 2011, 6:e22242.

\section{doi:10.1186/1297-9686-46-44}

Cite this article as: Rothammer et al:: The 80-kb DNA duplication on BTA 1 is the only remaining candidate mutation for the polled phenotype of Friesian origin. Genetics Selection Evolution 2014 46:44.

\section{Submit your next manuscript to BioMed Central and take full advantage of:}

- Convenient online submission

- Thorough peer review

- No space constraints or color figure charges

- Immediate publication on acceptance

- Inclusion in PubMed, CAS, Scopus and Google Scholar

- Research which is freely available for redistribution 